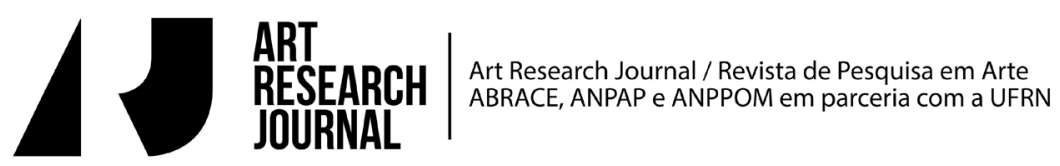

\section{Tecnoestética, interlocuções e afecções entre arte-vida}

\author{
Eriel de Araújo Santos \\ Universidade Federal da Bahia \\ eriel33@hotmail.com
}

O que nos afecta quando observamos a instalação "Genesis", de Eduardo Kac, ao entramos na "Sala Rubem Valentim" ou mesmo quando experienciamos o "Abramović Method", está associado às etapas de produção e apresentação de objetos e materiais que, articuladamente combinados ou criados, propõem dar sentido a algo que não é possível ser visto. Contudo, sua existência é inquestionável, provocando discussões que transitam entre o sagrado (alicerçado pela fé), mas não religioso, e o científico (amparado por leis predeterminantes). Assim, nessas e em tantas outras manifestações artísticas, nos deparamos com a instauração do que chamamos "estado de Arte", onde obra, autor e público se encontram num único ponto, a experiência artística.

Para John Dewey ${ }^{1}$, por exemplo, não há dúvidas sobre a importância dos resultados de uma experiência artística e sua contribuição para o conhecimento e reconhecimento do humano. Seja pela reverberação do som no espaço, pela presença de elementos físicos e dos fenômenos provocados pelos mesmos, pela atualização de dados virtuais, ou mesmo pelos resultados obtidos de interações promovidas pela performance do corpo do autor de uma obra ou daqueles que participam de uma apresentação artística, verificamos que essas experiências são possíveis através de uso de técnicas que conduzem as ideias ao campo da existência. Nesse percurso, surgem interlocuções que são capazes de reunir informações, aparentemente intercambiáveis, em um lugar de encontro entre a experiência e a teoria, a técnica e o acaso, a presença e as possibilidades de existir, a Arte e a Vida. Contudo, ao percebermos que as leis, criadas por nós, não são imutáveis, podemos avançar em discussões sobre a realidade e os valores que atribuímos aos fatos presenciados a cada instante.

A partir das experiências vivenciadas junto aos trabalhos citados no início deste texto, percebemos que os projetos, pertinentes a cada um, foram conduzidos por 
articulações de caráter multidisciplinares. Verificamos, então, a existência de atravessamentos conceituais e escolhas técnicas associadas às ideias compartilhadas entre arte, espiritualidade, ciência e vida. Todo trabalho, escolhido neste recorte, apresenta uma tecnoestética estrategicamente elaborada para atender aos objetivos presentes em cada processo criativo, seja pelo uso de tecnologias dos materiais, de métodos científicos, de apropriação de materiais "simbolicamente potentes" ou pela criação de objetos como representantes de signos transcendentais, metaforicamente identificados em suas formas.

No entanto, todos os resultados alcançados estão submetidos a um corpo, um "mecanismo" que, mesmo com suas próteses de ampliação da percepção visual e intelectual, está sujeito aos campos indecifráveis do Ser. Algo que escapa, muitas vezes, ao nosso entendimento, mas que se faz presente em nós, acompanhando nossas ações e construções de si, atuando como artistas ou não. Como afirma Gilbert Simondon,

A estética não é a única nem primeiramente a sensação do "consumidor" da obra de arte. É também, mais originalmente ainda, o feixe sensorial mais ou menos rico do próprio artista: um certo contato com a matéria enquanto trabalhada. Sentimos uma afecção estética ao fazer uma solda, ou ao enfiar um parafuso.... É um espectro contínuo que liga a estética à técnica... (Simondon, 1998, p. 256).

Quando um artista escolhe essa ou aquela técnica para apresentação de uma ideia, ele procura estabelecer conexões com a construção de um conhecimento em constante mutação, pois a obra resultante estará se contaminando com os meios em que ela esteja inserida e os seres que, por sua vez, interagem com o objeto ou sistema criado. Nessas interações, o tempo e o espaço estão unidos numa condição propícia para o acontecimento daquilo que identificamos como Arte. Nesse sentido, pensar a arte como um acontecimento nos conduz à ideia de que somente através da experiência é possível instaurar um "estado de arte" em nós. Um conhecimento dado pela duração contatada entre o corpo-Ser e os outros corpos, pois

\footnotetext{
A heterogeneidade qualitativa de nossas percepções sucessivas do universo deve-se ao fato de que cada uma dessas percepções estende-se, ela própria, sobre uma certa espessura de duração, ao fato de que a memória condensa aí uma multiplicidade enorme de estímulos que nos aparecem juntos, embora sucessivos. (Bergson, 1999, p. 74).
}

Quando Henri Bergson nos alerta para a existência de sobreposições de experi- 
ências num único momento, ele propõe pensarmos que o instante está articulado com outros lugares e outros tempos, não determinado pelas leis da ciência. $\mathrm{Na}$ arte, por conseguinte, algumas vezes o tempo se apresenta incompreensível pelas leis da lógica, por apresentar aspectos qualitativos. Com isso, por exemplo, o tempo de uma imagem ou ação artística nos conecta com outras experiências vividas e projeções no devir de uma situação multirreferencial. Além desses dados que se cruzam numa produção e fruição artística, há aqueles que se conectam com áreas de conhecimento relacionadas com a espiritualidade, a religião, por exemplo.

Para realizarmos uma análise de trabalhos que apresentam, em suas gêneses, uma natureza de caráter multidisciplinar, híbrido, é necessário recorrer a alguns pensamentos teóricos que tentam identificar metodologias capazes de conduzir a uma reflexão eficiente. O hibridismo, por exemplo, surge como uma ferramenta conceitual identificada em alguns procedimentos artísticos, em destaque para aqueles presentes na arte contemporânea, os quais envolvem áreas de conhecimentos distintos. Nesse sentido, os procedimentos artísticos e seus resultados ultrapassam as fronteiras tradicionais da arte e avançam em direção a outros "lugares", misturando linguagens, materiais, meios de produção e modos de apresentação.

Em muitos tratados sobre os modos de fazer e pensar a arte, percebemos um confronto entre as técnicas de produção, apresentação e a fruição da obra, na qual o caráter participativo se associa ao imaginário individual e suas interpretações possíveis. Salientamos, contudo, que o indivíduo é um constructo físico, emocional e intelectual, no qual podemos perceber dinâmicas significativas no seu modo de experienciar o dia a dia. Ao refletir sobre essas dinâmicas, identificamos na estética, definida por muitos filósofos e pensadores como um lugar de "análise do sensível", a possibilidade de articulação do pensamento com os sentimentos de atração e repulsa que afetam o corpo humano em seus múltiplos canais sensitivos, identificado por René Passeron ${ }^{2}$ como "[...] um território coerente, luminoso e científico, o da sensibilidade humana, e das ideias que dela emanam [...]". A estética estaria então associada àquilo que surge de uma interação entre o objeto e aquele que observa conduzido pelo reino das sensações e discursos epistemológicos.

$\mathrm{Na}$ instalação "Genesis" (Figura 1), de Eduardo Kac, por exemplo, identificamos a elaboração de uma metodologia criativa associada à intersemiose, pois na sua apresentação e discussão conceitual existem experiências relacionadas com a de

2 PASSERON, René. Da estética à poïética. In: Porto Arte, Porto Alegre, V.8, n.15, p.114, 1997. 
codificação e a ressignificação de um dado pertencente ao conhecimento religioso, deslocado para o campo da arte através de métodos experimentais científicos. Esta obra vem ocupando espaços distintos e provoca discussões sobre a vida.

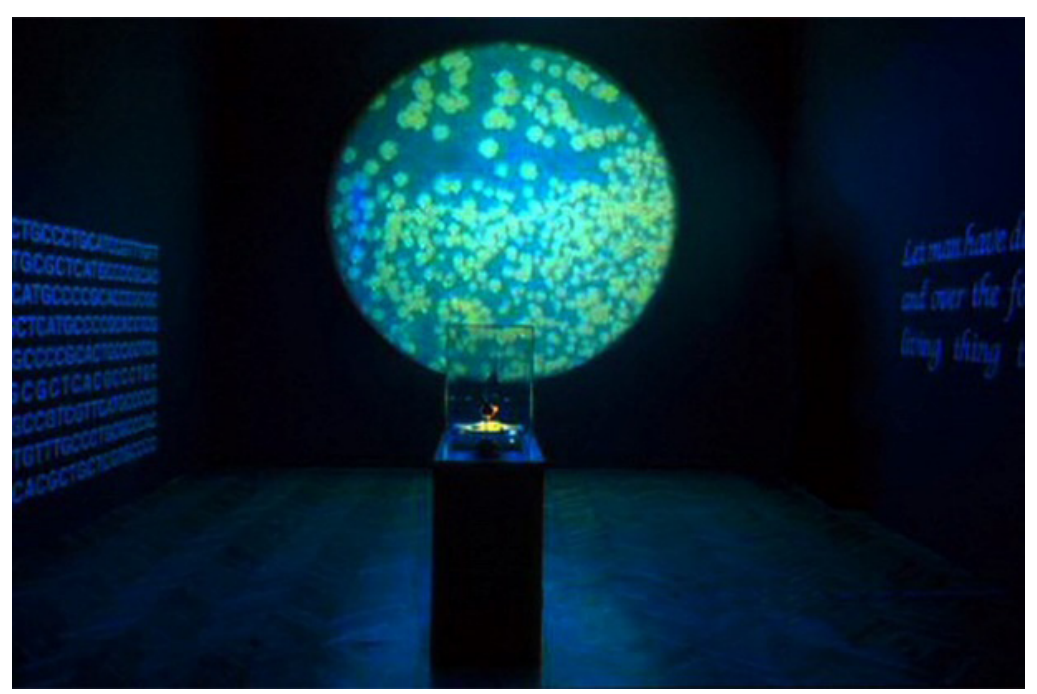

Figura 1. Eduardo Kac. "Genesis". Instituto Valenciano de Arte Moderna. Espanha. 2007.

Para Eduardo Kac, a arte "é o laboratório da liberdade" 3, no qual seu trabalho apresenta resultados identificados como bioarte, pois, ao manipular uma espécie viva, além de manter um comportamento ético, iniciado desde sua elaboração, ele usa processos biotecnológicos no seu modo de fazer arte. Em "Genesis", Kac escolhe uma frase do livro Gênesis, da Bíblia, e resolve interpretar, à luz de uma ficção criada por ele, a manipulação e o domínio sobre a vida tão discutida ao longo dos anos, seja pelas descobertas científicas e pelos comportamentos sociais, seja pelos dogmas religiosos. Para tanto, após escolher uma frase da Bíblia, a qual "autoriza" o homem a manipular a vida, Kac propõe uma decodificação do código verbal ao código Morse, deste ao código genético e conclui com a produção de gene sintético baseado nessa decodificação. O resultado artístico é resolvido numa instalação, onde o espaço físico comporta uma apresentação desses elementos visuais, verbais e biológicos.

Observamos neste trabalho de Kac uma espécie de disruptura dos códigos e crenças defendidas pela arte, pela ciência e pela religião, agora condensados numa obra que infere dúvidas sobre os crentes e os céticos, problematizado por uma tecno-estética amparada pela fusão de códigos semióticos e processos biotecnológicos. Algo que se afasta da estética tradicionalista do fazer artístico.

3 Eduardo Kac. http://www.ekac.org/puc.2010.html. 
Assim como existem trabalhos artísticos que se relacionam com métodos científicos, há aqueles que pertencem aos códigos definidos por uma religião, seguindo suas crenças e mitos, muitas vezes representados em vários meios expressivos. A obra produzida pelo artista Rubem Valentim é uma dessas referências, pois seu processo criativo está integrado aos ritos e significados oriundos das religiões de matriz africana.

Em 1998, o Museu de Arte da Moderna da Bahia inaugurou a Sala Especial Rubem Valentim no Parque de Esculturas, uma exposição permanente contendo parte de seus trabalhos, intitulada "Templo de Oxalá" (Figura 2). Ao recriar símbolos afro-brasileiros, Rubem Valentim estabelece conexões intersemióticas entre a arte e o transcendental. Suas peças escultóricas apresentam estéticas que podem ser associadas a totens de comunicação, objetos sagrados ou signos de uma linguagem desconhecida.

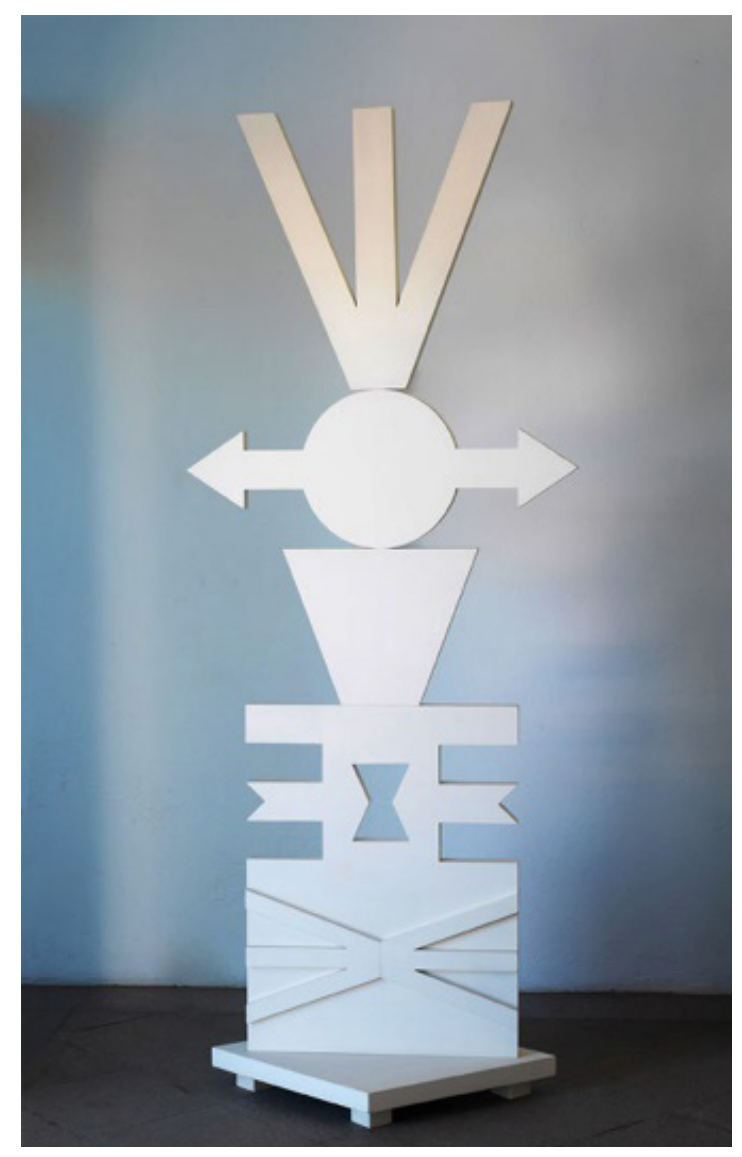

Figura 2. Rubem Valentim. "Templo de Oxalá". Museu de Arte Moderna da Bahia.

Ao discutir sobre a escultura contemporânea do Brasil, Marcelo Campos estabelece importantes nexos de significação e interpretação dos resultados obtidos pelos ar- 
tistas que exploram a tridimensionalidade física. Ao apresentar a obra de Rubem Valentim, ele a insere numa reflexão sincrônica e diacrônica com as manifestações totêmicas presentes na história da arte, destacando as peculiaridades existentes no processo criativo dos artistas brasileiros, com especial atenção para aqueles que incorporam elementos das culturas indígenas e africanas em seus modos de fazer arte.

Ao fazer referência às experiências da África, Marcelo Campos afirma que "a situação se adensa, pois tínhamos nos altares, também chamados de pejis no candomblé, os objetos tribais, totêmicos, como elementos de adoração coletiva, amuletos [...]" (Campos, 2016, p. 280). Essas referências se encontram presentes no processo criativo de Rubem Valentim, onde destacamos sua participação ativa nos terreiros de candomblé em consonância com suas atividades artísticas ${ }^{4}$. Os resultados são obtidos a partir do uso de elementos geométricos e construções que se aproximam do concretismo. Contudo, esses signos, criados por ele, compõem uma vasta possibilidade de significação apoiada numa discussão sobre o reconhecimento das expressões da cultura afro-brasileira, como diz Campos:

Um exemplo de tais discussões e descobertas dos elementos recorrentes nos terreiros é a obra de Rubem Valentim, que se apropria de situações geométricas e as amalgama, junta-as, a ponto de não lermos sinais individualizados. Em Valentim, os signos são como rememorações distantes, já que o artista os utiliza, trabalhando as cores nas arestas, nas laterais, nos avessos, sem jamais criar associações muito diretas. (Campos, 2016, p. 280).

Mais uma vez percebemos que as técnicas usadas para a construção de uma obra se associam à diversidade dos modos operacionais engajados no modo de viver de cada artista. Valentim propõe desvios nas leis preestabelecidas pelos símbolos religiosos e constrói uma obra onde o transcendente se torna concreto em suas esculturas pintadas, e o significado das mesmas geram dúvidas durante as tentativas de decodificação. Uma obra que se aproxima a uma mis en abyme ${ }^{5}$, pois, a partir de elementos simbólicos conhecidos, encontramos a possibilidade de construção de outras narrações interpretativas.

4 Disponível em: <http://museuafrobrasil.org.br/pesquisa/indice-biografico/lista-de-biografias/2016/11/01/rubem-valentim>

5 Termo usado por André Gide para definir as "narrativas em abismo", aqui associado às interpretações múltiplas de um símbolo verbal ou visual. 
Se toda arte é feita com os meios do seu tempo, acreditamos que o momento atual seja de pluralismo e uso de materiais e técnicas desenvolvidos em vários tempos e lugares, inscritos nas culturas pertinentes a cada espaço geográfico da Terra. Entendemos, por isso, que o uso de estratégias, usadas na produção artística contemporânea, tem contribuído para o surgimento de um fértil campo de pesquisa processual e teórico. Assim, em cada obra apresentada, percebemos que existem "eventos" que eclodem da interação entre a obra, o autor, o público e as realidades. As técnicas, os métodos e as tecnologias, usadas na produção dessas obras, colidem com um corpo, o corpo humano. É aí que se dá a instauração da experiência artística, um campo de potência presente num corpo, agora como lugar da experiência, lugar da performance.

Acompanhar o pensamento de Tracey Warr (2000) para o entendimento da performance e sua contribuição para a expansão das manifestações artísticas incide no reconhecimento do papel do corpo como lugar para acontecimentos, algumas vezes no próprio corpo do artista, outras quando desenvolvida coletivamente em ações colaborativas ou participativas. Então, o corpo deixa de ser representado pelas técnicas tradicionais das artes plásticas e passa a ocupar o próprio lugar da obra de arte. Para tanto, as técnicas da dança, teatrais e circenses, por exemplo, são responsáveis por conduzirem a uma estética mestiça.

Nas peregrinações processuais executadas pela artista Marina Abramovic, por exemplo, busca-se algo que escapa ao entendimento da existência. Abramovic criou então um método específico para essa "caminhada". Porém, esse método só tem eficiência se o participante estiver apto a reconhecer que está num caminho sem destino predeterminado pelas leis que regem o comportamento social. É preciso "despir-se" das armadilhas incrustadas no corpo e na mente, acumuladas ao longo da trajetória de cada indivíduo.

Em "Terra comunal", Abramovic reuniu um significativo conjunto de trabalhos e registros de performances realizadas durante sua carreira artística. Dentre estes, destacamos a obra na qual o público pode conhecer e participar do Método Abramovic. Este trabalho se distancia das atividades desenvolvidas até então pela artista, pois o público é convidado a praticar uma série de atividades de imersão durante duas horas. O corpo é o lugar onde a obra acontece, pois os participantes, antes de entrarem no espaço, deixam seus pertences: documentos, chaves, ce- 
lulares, entre outros. Usando apenas suas roupas e pés descalços, o público está pronto para interagir com os objetos instalados e praticar o Método Abramovic. A sede do SESC-Pompeia, em São Paulo, foi o lugar usado por ela para instalar as peças, construídas especificamente para conduzir os participantes a experienciar o silêncio como parte fundamental da fruição da obra.

A quietude esperada dos participantes é um fator preponderante para que eles possam experienciar um projeto artístico que propõe nos afastar da aceleração provocada pelo desenvolvimento tecnológico e científico, enfatizando os valores intrínsecos ao humano, aqueles presentes na estrutura do nosso corpo e revelados pelo nosso Ser. Para isso, o Instituto Marina Abramovic construiu objetos com matérias que, em contato com o corpo dos participantes, apresentam uma função capaz de conduzir "energias" que emanam de suas estruturas físicas. Uma fruição pela presença.

Na pesquisa em processos de criação em artes visuais, a escolha de materiais e procedimentos, por sua vez, constitui uma etapa essencial para o desenvolvimento de um determinado trabalho. Num mundo em que tudo se encaminha para a virtualidade, não podemos deixar de lembrar a nossa relação com a presença em si, pois essa experiência configura um dos elementos essenciais da criação artística e sua interlocução com a vida. Afinal, a arte não se dá somente pelo sentido, mas também pela presença. De acordo com Gumbretch (2010, p. 13), a palavra "presença" não se refere (pelo menos, não principalmente) a uma relação temporal. Antes, refere-se a uma relação espacial com o mundo e seus elementos constituintes. Uma coisa "presente" pode ter impacto imediato em corpos humanos.

Quando pensamos nas reconfigurações das técnicas, estratégias, espaços e condições adversas da produção artística contemporânea e a redefinição da realidade, o lugar e a temporalidade de uma obra contêm outros modos de acontecimentos, onde as interlocuções com os modos de fazer, as técnicas, materiais e espaços são escolhidos estrategicamente para tornar visível um ideal inexistente. Um futuro antecipado, presente. Assim, os metais, madeiras e cristais, usados para o exercício do Método Abramovic, são materialidades que tornam possíveis experiências de "coisas" ausentes em materiais presentes, junto aos seus corpos, pois

Somente o homem possui a capacidade de elaborar imagens de coisas ausentes, utilizando essas imagens nas mais variadas situações também imaginárias. Um objeto observado pelo olho, pode remeter 
a outras imagens formadas a partir do olhar, o qual não é limitação da percepção do objeto em suas características físicas imediatas, o olhar é ir além, é captar estruturas, é interpretar o que foi observado. (Zamboni, 1998, p. 56).

A partir da observação dos objetos (Figura 3), usados no Método Abramovic, instalados nos espaços do SESC-Pompeia, é possível ativar a imaginação e dar início a um processo de fruição que se inicia com o olhar, pois logo depois somos orientados a fechar os olhos. Nesse momento, a proposta é ver e ouvir o que não é visto pelos olhos ou escutado pelos ouvidos, pois os olhos se fecham e o som é anulado por fones bloqueadores do ruídos. Assim, a experiência artística se dá por imersão em si mesmo e pelo contato do corpo com os materiais presentes no espaço, esteja este corpo sentado, em pé ou deitado. Uma performance compartilhada entre o público, o espaço, os objetos e o Método Abramovic.

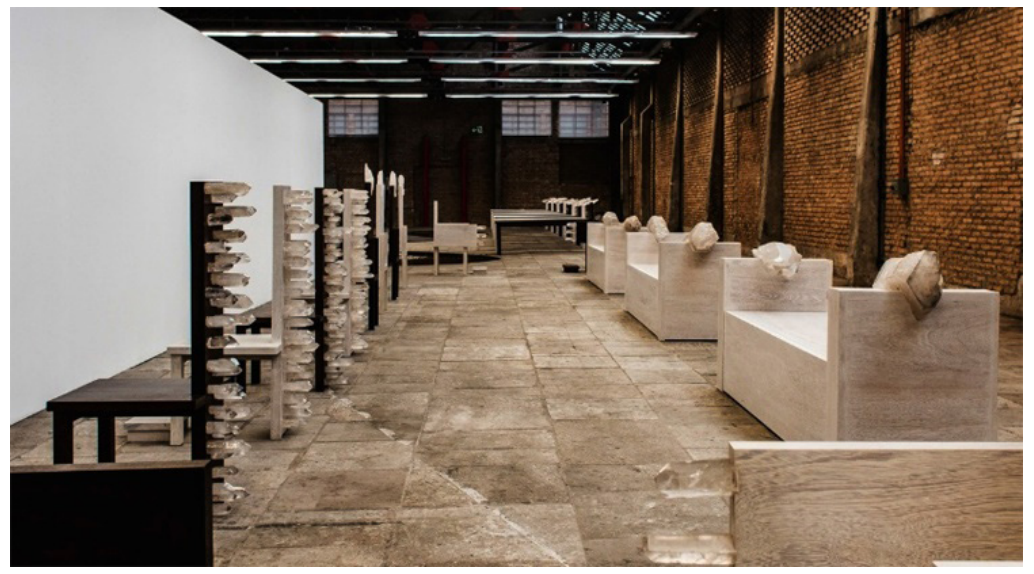

Figura 3. Objetos construídos para uso no Método Abramovic. Sesc-Pompeia.

Ao ler a "Carta a Jacques Derrida", de Gilbert Simondon, por exemplo, podemos analisar o quanto os modos de fazer e apresentar um objeto de arte promove condições para interlocuções entre o que foi feito e as qualidades inerentes ao material utilizado e suas significações. Seguindo esse pensamento, percebemos que as escolhas dos materiais, o posicionamento dos objetos construídos e os posicionamentos dos participantes do Método Abramovic foram meticulosamente estudados e planejados para ocupar o espaço e constituir uma estética de integração entre corpo, objetos e lugar. Nesse momento, essa integração se dá pela lentidão, pois

As dúvidas e reivindicações apressadas desaparecem quando, no lugar de conceber a lentidão como deficiência, ela passa a ser entendida como uma escolha. Uma escolha que nada tem de passivo... Seu uso pode inclusive reavivar o gosto pelo realismo mágico formulado pela estética da velocidade. (Sant'anna, 2001, p. 18). 
Quando Denise Sant'Anna aborda sobre as velocidades de interação do corpo junto aos eventos ocorridos num determinado território de experimentações sensíveis, ela propõe uma discussão que afasta a ideia preponderante da inteligência cerebral. Com isso, as relações entre arte e corpo são evidenciadas nas atividades que envolvem a performance, se valendo, muitas vezes, de estratégias artísticas, estéticas ou simbólicas. Daí surgem fusões multidisciplinares, nas quais os binômios arte-vida, arte-ciência, arte-religião, arte-política, entre tantos outros, proporcionam direcionamentos para outros estados de consciência, aqueles situados nos intervalos. Nesses intervalos é possível encontrar sinais que podem tornar as atitudes cotidianas do indivíduo mais potentes, pois "[...] na experiência estética surge um fator de mudança que, ao unir o gozo estético com um particular efeito subjetivo, ao introduzir um conhecimento diverso, se transforma em uma experiência de sentido" (Goldstein, 2005, p. 18).

No dia a dia somos confrontados com um turbilhão de ações e expectativas formadoras de um horizonte hipnotizante. É necessário proporcionar pausas para que possamos perceber nas nuances, outros caminhos, outras condutas. Nesse sentido, como reflete Georges Didi-Hubermann, "Dar exclusiva atenção ao horizonte é tornar-se incapaz de olhar a menor imagem, aquela imagem-vaga-lume cujo lampejo inesperado pode ser o primeiro operador político de protesto, de crise, de crítica ou de emancipação" (Hubermann, 2011, p. 56). Assim, acreditamos que as propostas artísticas aqui analisadas corroboram para o surgimento de "lampejos" capazes de reconfigurar ideias e gerar ações de pensamentos atualizados a partir das experiências vivenciadas e interpretadas por cada um.

\section{Referências}

BERGSON, Henri. Matéria e memória, ensaio sobre a relação do corpo com o espírito. São Paulo: Martins Fontes, 1999.

CAMPOS, Marcelo. Escultura contemporânea no Brasil. Salvador: EPP, 2016.

DEWEY, John. Art as Experience. New York: Perigee Books, 1938. 
GOLDSTEIN, Gabriela. La experiencia estética, escritos sobre psicoanálisis y arte. Buenos Aires: Del Estante, 2005.

GUMBRECHT, Hans Ulrich. Produção de presença: o que o sentido não consegue transmitir. Tradução Ana Isabel Soares. Rio de Janeiro: Contraponto: Ed. PUC-Rio, 2010.

HUBERMANN, Didi. A sobrevivência dos vaga-lumes. Belo Horizonte: Editora UFMG, 2011.

PASSERON, René. Da estética à poïética. Porto Arte, Porto Alegre, v. 8, n. 15, 1997.

SANT'ANNA, Denise Bernuzzi de. Corpos de passagem, ensaios sobre a subjetividade contemporânea. São Paulo: Estação Liberdade, 2001.

SIMONDON, Gilbert. Sobre a tecno-estética: Carta a Jacques Derrida. In: ARAÚJO, Hermetes Reis de. Tecnociência e Cultura, ensaios sobre o tempo presente. São Paulo: Estação Liberdade, 1998.

WARR, Tracey. The artists' body. Londres: Phaidon, 2000.

ZAMBONI, Silvio. A Pesquisa Em Arte, um Paralelo Entre Arte e Ciência. Campinas: Autores Associados, 2001.

\section{Internet}

KAC, Eduardo. Entrevista com Luísa Sandes. Disponível em: <http://www.ekac. org/puc.2010.html>. VALENTIM, Rubem. Disponível em: <http://museuafrobrasil. org.br/pesquisa/indice-biografico/lista-de-biografias/2016/11/01/rubem-valentim $>$ 